\title{
Evolution of VR Technology to Art Design Education in the Digital Age
}

\author{
Zhang Rui \\ Nanyang Institute of Technology, Nanyang Henan, 473004, China \\ Master of Art and Design \\ Henan University, Lecturer, Nanyang Institute of Technology,Art and Design \\ skycoco616@163.com
}

Keywords: VR technology; Art design; Education; Application

\begin{abstract}
In the digital era of rapid economic and technological development, the use of VR technology in the art design education has changed the previous teaching model, using immersive scenes to increase the degree of concentration in learning to improve learning efficiency. Let students perform practical operations in a virtual environment, which could turn traditional single teaching into a student-centered interactive mode. VR technology can turn each student into a "Master Ma Liang" and create a soulful artwork in a virtual environment.
\end{abstract}

\section{Introduction}

In recent years, China's education concept has developed rapidly, and the traditional inculcation education mode has been phased out and replaced by modern educational means. These means pay more attention to the guidance of students' thinking ability and the cultivation of their innovative ability. Among them, VR (Virtual Reality) technology has been widely used in many fields of education, including art design, because it can create realistic teaching situations and improve students' interest in learning. In particular, with the continuous development and progress of science and technology, the current technology of VR products and related equipment is becoming more and more mature, and its cost is still further decreasing. This also objectively promotes the application of VR technology in design education and gradually becomes a reality. The author discusses the application of VR technology in modern art design education combined with his own years of practical experience. And it is hoped that this study can be used for reference in related teaching work.

\section{Technical Analysis of Art Education and Virtual Reality}

\section{Art Education}

Art design education is a comprehensive concept. To understand art design education, we must first understand what is "design" and "art design". The word "design" is divided into "imagination" and "plan". The simplest definition of "design" is a "purposeful creation". Broadly speaking, design originated from the stone age of mankind's earliest creation. In a narrow sense, the design began after the Industrial Revolution where the social division of labor and professional designers began to appear. Art design involves all aspects of human life, both functional and aesthetic designs. It integrates art and technology, co-ordinates the traditional design of handicrafts and the modern design of large-scale industrial production, achieving the common development of both ${ }^{[2]}$.

Art and design education is a comprehensive education that combines art and art design. Art design education can not only cultivate high-quality professional talents through a series of professional knowledge transfer, but also enhance people's beauty and cultivate their sentiments, thus realizing the full development of people.

\section{Analysis of VR Technology in Digital Age}

Virtual Reality is abbreviated as VR. It is the use of computers to simulate a three-dimensional virtual environment, and this environment is not static, it can change as people change in the virtual environment, giving people an immersive sense of simulation. This technology was concerned by 
the engineering and scientific communities in the 1990s. It incorporates multiple information technology branches such as computer graphics, digital image processing, multimedia technology, and sensor technology. Its evolution has promoted the rapid development of various large-scale projects such as intelligent engineering and human-computer interaction. Virtual reality technology has three characteristics: Immersion, Interaction, and Imagination.

The immersive sense of virtual reality is also called liveliness. This computer-structured virtual world makes users feel like they are on the ground. By confusing the user's audiovisual, it cannot distinguish between virtual and reality. In the virtual environment, the sense of smell and taste are created to be real, and the contact with the virtual object is achieved through a sensor or the like, so that the user is immersed in the real virtual world.

Interactivity refers to the interaction between users and virtual space in a virtual environment. In a virtual environment, users can interact with the objects as if they were in the real world. For example, when you pick up a ball in a virtual environment, you can touch its presence and feel its weight. After throwing it on the ground, you can also play it up. This is the interaction with virtual items, called interactivity.

Conceptuality refers to the infinite possibilities of imagination in the virtual world. Even if it is something that is not in the real world, we can also realize it so that humans can observe and feel more fields and create any environment that humans can think of. This kind of state can inspire people's imagination very well, and people can make a cognitive leap. Imagine how exciting the immersive experience was when we abandoned the traditional design painting approach and created it in a fairly realistic virtual space. In addition, the virtual reality world is also multi-sensory, that is, it can simultaneously mobilize people's vision, hearing, smell and taste. Users can operate virtual environments like the real world. This model subverts the previous human perception. People can not only be exposed to the virtual environment, but also can combine the virtual environment with the reality and realize many new areas of exploration.

\section{Fusion of VR Technology and Art Design Education}

Combining these three characteristics of immersion, interaction, and conception of VR technology, applying VR technology to modern art design education is a good choice.

\section{International Frontier VR Education Practices}

A software exhibited at the BETT summit in the United Kingdom can use infrared rays to sense the movement of fingertips to play music. We can download a music tutorial at home at any time and learn without the need for physical instruments, greatly reducing students' learning thresholds, changing the previous teaching model, and helping teachers and students improve their teaching efficiency and learning results. A medical VR product on display at the SXSWedu Summit in Silicon Valley, USA can make us observe organs and rotation manipulation from all angles. This new learning model breaks many limitations in traditional medical education, and can be better extended to the treatment of patients in the future, which can be considered a medical education revolution. In the era of rapid development in digitalization, this new attempt has been continuously occurring ${ }^{[3]}$.

\section{Opportunities and challenges brought by VR technology to art design education in China}

In the contemporary society that emphasizes quality education, the use of high-tech educational equipment to improve students' interest in learning and tap the learning potential is particularly important. The art and design profession needs to cultivate talents with extraordinary creativity, imagination and practical skills. At present, the teaching methods of art design in our country are too monotonous, and the pertinence of class assignments is not strong. Sometimes the teachers are too biased in basic knowledge education and ignore the teaching of the practical application of the professional itself. Teaching arrangements for theoretical knowledge and practice should be closer to student needs. Students always sit in the classroom step by step to complete the basic operations for many years, and it is difficult to stimulate creativity by simply brainstorming with paper and pen. This kind of inefficient education model can easily lead to students out of touch with society, and it is difficult to adapt to jobs after graduation. The purpose of the teaching of the basic arts and design 
education course is relatively clear. However, the single teaching method and the outdated classroom practice are particularly difficult for the cultivation of professional talents. The cultivation and training of creative thinking occupies a pivotal position in the art design education system. Breaking away from traditional imprisonment, it is extremely urgent to develop students' ability to think independently. We should use effective methods to train creative thinking skills, lead students to learn from a single basic theoretical knowledge, enable students to master the correct design thinking, and successfully find breakthroughs in innovation.

\section{Case analysis of Applied Teaching}

Taking online 3D virtual indoor scene art design as an example, the roaming of online virtual reality is divided into three levels: the user interface layer, the computing logic layer and the data and storage. The computing logic layer can also be divided into many layers, which can be independently designed and developed for each logical unit. By storing the geometric modeling data in different XML files, the key data in the VRML modeling are introduced into the light data to make the design of the application more flexible. The data storage layer can be invoked and shared by different applications, and can also not affect the application's computing scene and user logic when the data storage mode is completely changed. The calculation logic layer can be divided into many layers, depending on the actual situation. Through standardized data types, many basic data can be reused and shared, which is conducive to the development of heterogeneous systems.

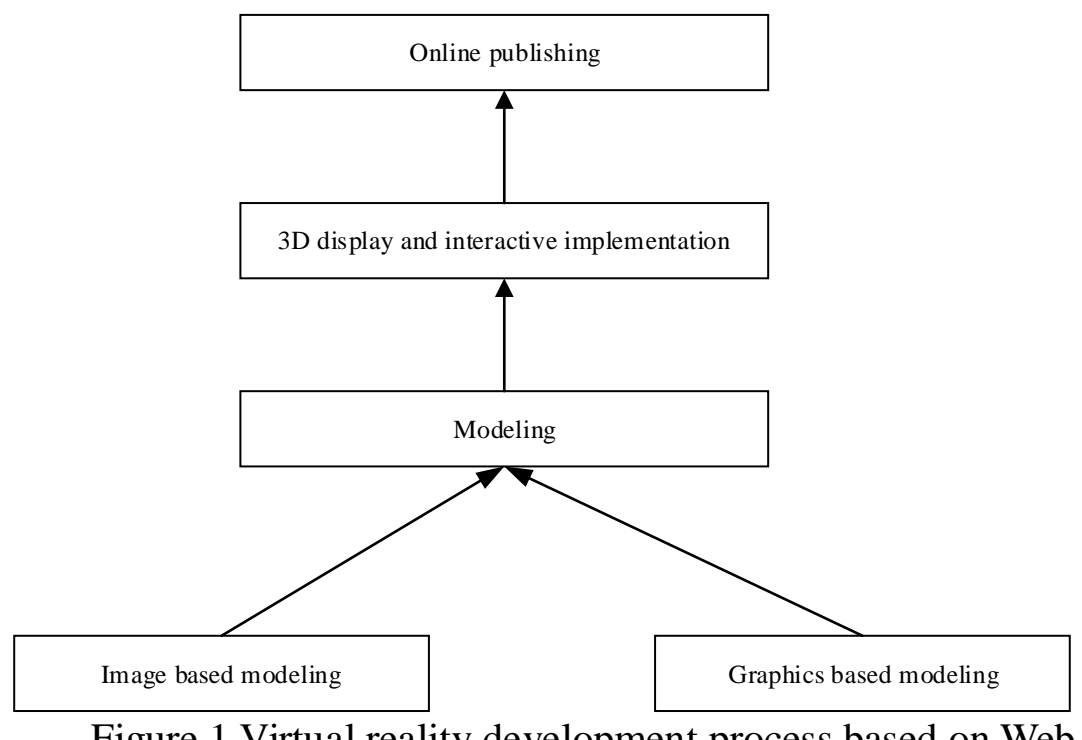

Figure 1 Virtual reality development process based on Web

WEB's virtual reality development mainly consists of three parts: 3D modeling, 3D display and interaction realization, and online publishing. Their relationship is shown in Figure 1. The main steps are as follows: first, create the effect of 3D with planar images. After obtaining the set of 2D images, we can do image penetration, realistic graphics transformation, image mosaic, image synthesis and clipping, and create $3 \mathrm{D}$ effect ${ }^{[4]}$. Compared with the geometric model scene generation algorithm, it has less computational complexity and is not limited by the complexity of the scene, and the requirements for hardware are not as high as geometric modeling. It is easy to implement on the Internet. Then it is based on the development of network technology. The last is to compress the user's browsing wait time. The design effect of the three-dimensional interior design simulation system is shown in Figure 2. 


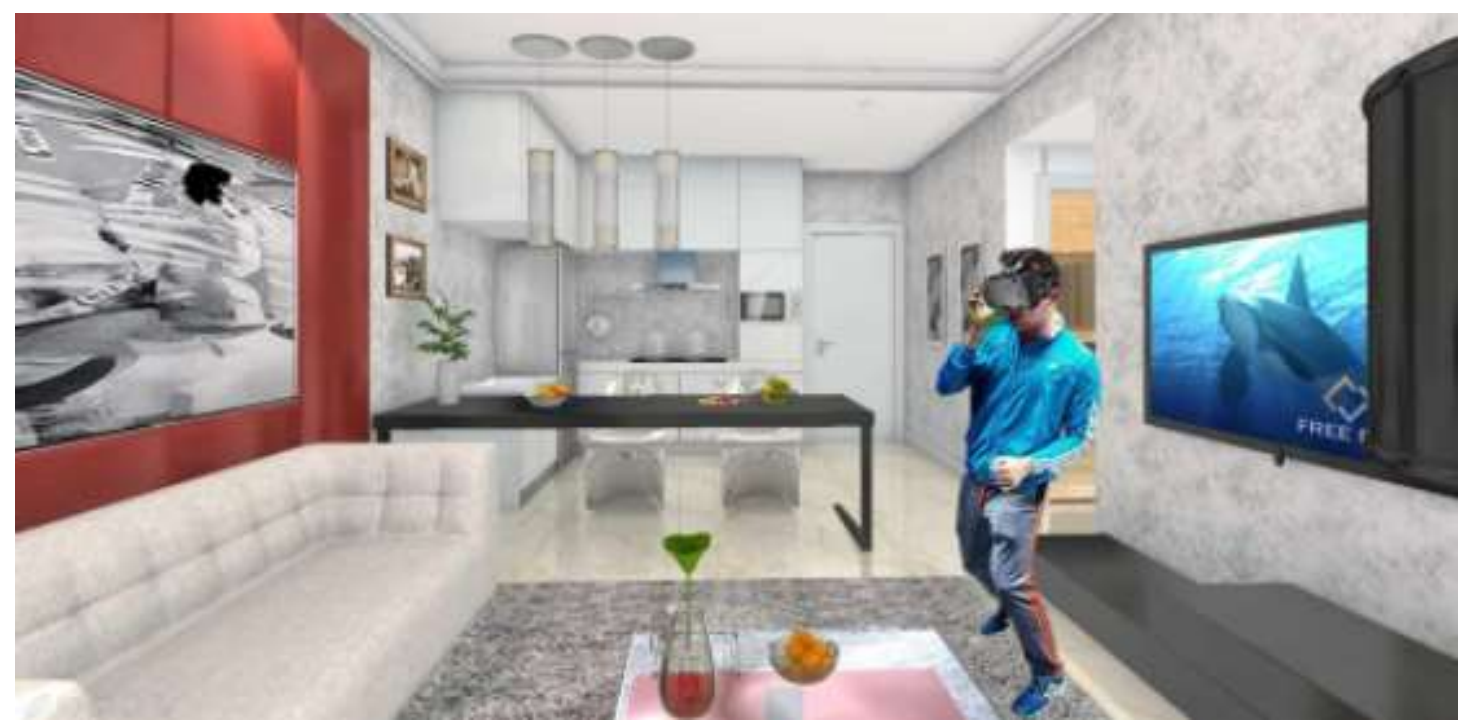

Figure 2 System design effect diagram

As shown in Figure 2, the application of VR technology to the interior scene art design can allow students to feel their own design works and allow students to immerse them fully and give the students a real feeling.

\section{Conclusion}

Throughout the development of our country's art design education, we have been exploring and progressing from the beginning of enlightenment, creation, stagnation, recovery and transformation to today's rapid development. In this era of rapid development of science and technology, high-tech education equipment is not widely used in China, and we still have a long way to go in exploring research and development. However, this is an era in which both challenges and opportunities coexist. With the continuous development of VR technology software and hardware, innovation in teaching will continue to emerge. We hope that more VR based learning software will change our life as early as possible.

\section{Reference}

[1] Lawrence A. Repositioning the Essential Art in Collaborative Technology-Mediated Design Education[J]. 2013, 13(3).

[2] Wood J. Open Minds and a Sense of Adventure: How Teachers of Art \& Design Approach Technology[J]. International Journal of Art \& Design Education, 2010, 23(2):179-191.

[3] Chulvi V, Mulet E, Felip F, et al. The effect of information and communication technologies on creativity in collaborative design[J]. Research in Engineering Design, 2016, 28(1):1-17.

[4] Purser R. The Cultural Aesthetic of Virtual Reality: Simulation or Transparency[C]// Human computer interaction. IGI Global, 2001:214-231.

[5] Yu D, Peng L. When does Inferring Reputation Probability Countervail Temptation in Cooperative Behaviors for the Prisoners' Dilemma Game? [J]. Chaos, Solitons \& Fractals, 2015, 78: 238-244. 